\title{
Impacts of Different Mobile User Interfaces on Student Satisfaction for Learning Dijkstra's Shortest Path Algorithm
}

\author{
http://dx.doi.org/10.3991/ijim.v8i4.3860 \\ Mazyar Seraj ${ }^{1}$ and Chui Y in Wong ${ }^{2}$ \\ ${ }^{1}$ Limkokwing University of Creative Technology, Malaysia \\ ${ }^{2}$ Multimedia University Malaysia
}

\begin{abstract}
This paper describes an experimental study of university students learning Dijkstra's shortest path algorithm on mobile devices. The aim of this study is to investigate and compare the impacts of two different mobile screen user interfaces on student satisfaction upon learning this technical topic. A mobile learning prototype was developed for learning Dijkstra's shortest path algorithm on Apple iPhone 4s operated on the iPhone operating system (iOS) and Acer Inconia Tabs operated on an Android operating system. Thirty students who are either currently studying or had previously studied the course "Computer Networks" were recruited for the usability trial. At the end of each session, student satisfaction with respect to their satisfaction with the two mobile devices was measured using QUIS questionnaire. Although there is no significant difference in student satisfaction between the two different mobile screen interfaces, the subjective findings indicate that the Acer Inconia Tab gained higher scores than the Apple iPhone 4.
\end{abstract}

Index Terms-Dijkstra's shortest path algorithm, mobile devices, mobile user interface, small screen interface, user satisfaction.

\section{INTRODUCTION}

Mobile-based learning technology is a new generation of e-learning technology that permits learners to carry out learning activities and practice course content more frequently, anytime and anywhere, through mobile devices using smart phones, tablet PCs and PDAs [13],[16],[17]. Although previous research has provided findings with regards to the capabilities of mobile devices in learning and teaching, research is still required to investigate the impacts of small screen devices on user satisfaction when used in mobile-based instructional applications, in view of the different screen sizes of mobile devices [12].

The main objective of this paper is to investigate and compare the impacts of different mobile user interfaces on student satisfaction, using a mobile-based learning prototype. A second objective is to design and develop a usable mobile-based learning prototype based on the identified usability and user interface design guidelines presented by [9] and [10]. The developed prototype focused on designing mobile-based course content for Dijkstra's shortest path algorithm. Dijkstra's shortest path algorithm is a technical subject, which is taught to computer science students. The prototype was developed for two different touch-based mobile devices, the Apple iPhone 4 and the Acer Inconia Tab. The computer science students generally need to fully comprehend this topic in order to master the theoretical concept and practice of the subject [13]. When the Dijkstra's shortest path algorithm is presented on small screen devices with different processing capacities such as limited storage and performance restrictions, designers and developers need to incorporate an appropriate design strategy to assist students learn this complex concept [3],[4],[7].

\section{LITERATURE REVIEW AND RELATED WORK}

Designing an effective user interface for a mobile-based application is strongly emphasized by various mobile learning studies [9],[10],[13]. As such, usability of a mobile-based application is one of the most important attributes that should be considered when designing and developing a mobile-based learning application [9],[10]. An efficient user interface for mobile device is essential to create a usable and effective mobile-based information system because it helps increase user satisfaction and provides greater interactivity for persons using mobile and handheld devices for learning.

\section{A. User Interface Design for Mobile Applications}

Reference [9] presents four guidelines to desig a usable interface for mobile-based applications:

\section{1) Small Screen Display}

The small screen size of mobile devices represents challenges with regards to designing content effectively and organizing as much information as possible on a small screen display [21]. The restriction of small screen devices gives rise to other restrictions during the design phase of a usable mobile-based learning application [9],[21]. For instance, small screen displays trigger a more difficult reading process that directly impacts the normal pattern of eye movements and indirectly influences human interactions [25]. The information and content displayed on mobile-based application screens must consider reading speed, and the effect smaller text has on it. As a result, information should be organized into small chunks to provide the information in $n$ more effective manner [22]. Frequent scrolling and the number of touches by the users should be reduced. The height and width of an application screen page should not exceed the screen size of the target mobile devices [9].

\section{2) Relevant Information Display}

Presenting irrelevant information not only can confuse novice learners [8]. Relevant information must be displayed on each page of the application because of the 
restrictions and limitations imposed by the screen display size [9]. The most important information should be located at the right top corner to ease the readability. Empty and blank spaces should be designed with great care to avoid misleading or confusing users [9].

\section{3) Navigation}

Success or failure of a usable mobile-based application displayed on small screen devices is determined to a great degree by the selection of appropriate navigation structures [22]. Consistent navigation can support and maintain learner satisfaction while learning on a mobile learning application [9]. [23] suggests reducing complicated navigation by using simple menu options, which are already used in existing mobile devices, which will make users more comfortable using a more usable navigation method. Another two important considerations that can make navigation more fluid are decreasing the number of touches by users and changing the text input method by selecting the text from a menu list [8],[23].

\section{4) Consistency}

Consistency is one of the most important and fundamental usability principles to consider when designing a usable interface [11]. In particular, consistency of mobile contexts is very important because of the restricted screen size of mobile devices [9]. Moreover, consistency is defined by [24] as a cover for interface design and the task usefulness structure of a learning application. Thus, information needs to be located in the same locations in the interface to trigger consistent user actions [9]. For instance, similar buttons must be positioned in the same place on every page of the application.

\section{B. Usability}

Usability defines the quality of the user interface design and interaction of an application. Usability can be measured by the quality of learner experience during the interactions with the user interface of an application [11]. The advantages of usability are: (i) reducing the time and cost of training, (ii) reducing the errors that the user encounters during their interaction with the system, (iii) increasing learning performance and user satisfaction, and (iv) improving the quality of interaction with the interface [6],[13],[14],[15]. Thus, a set of design principles should be followed to provide an acceptable mobile-based learning application in terms of usability. We also took user interface limitations of a mobile-based learning applications such as small screen size, poor resolution, limited storage facility and lower processing capacity into account [4],[7],[26]. Finally, the mobile user interface must be designed in a simple way without any complexity, the size of output files must be reduced as much as possible, and the application must not involve high processing capacity.

\section{Mobile Technolog}

\section{D. y and Mobile-based Learning Application}

In developing mobile-based learning applications, some research studies have produced course content applications based on small screen devices. Four mobile-based course content learning applications have been developed by [9],[13],[19],[20].

According to [19], Adobe Flash CS3 was deployed to develop an application for learning English as a second language. This provides a reference to integrate two components in developing a mobile learning application on content and interface design. Content should be divided into various chunks so that each chunk represents a oneinterface screen page. In terms of the user interface, [19] had an optimized screen resolution via brightness and screen contrast that was controlled by the users. Adobe Flash CS3 was used to give learners full control to select and play each lesson slide by slide. At the end of the lesson, students could repeat the current slides, proceed to the following lesson, or complete the exam questions. Meanwhile, he used native speaker voices to improve the learners' listening experience, associating sounds and texts to assist learners. In order to accelerate the learning process, the researcher also used exercises to motivate and enhance learner performance upon concluding each unit. The results indicated that the project could improve learner satisfaction by permitting students to learn at any place and any time at individual pace with ease of use to enhance their pronunciation, especially their listening skills [19].

Reference [9] presented usability guidelines that focus on the user interface in terms of usability theoretical frameworks, possible restrictions and the unique properties of small screen interfaces. Three categories for usability of a mobile-based learning application were formulated, consisting of user interface design, human interaction and user analysis. These three categories, in turn, are supported by 10 golden usability guidelines for designing an effective, user friendly and usable mobile interface to support learning through mobile and handheld devices. An application was developed which is called Mobile Learning Course Manager (MLCM) to demonstrate the impacts of the proposed usability guidelines. The user interface of MLCM can be deemed as usable because it is learner centered, which was a primary consideration for designing the application. The application provides announcements, assessments and a timetable, three useful main menu options for registering MLCM [9],[5].

Reference [13] presents a study of User Interface Design (UID) principles and requirements for utilizing mobile devices as instruments for mobile learning. This study is supported by a suitable design architecture and learning theories. The objective of the study was to examine the design principles and requirements required to develop a course content application based on mobile devices [13]. Besides, the second objective is to produce a course content mobile-based learning prototype for System Analysis and Design (SAD) course for students. This is based on the principles, guidelines and requirements, which were identified as a powerful design tools for mobile-based applications. Finally, a survey was used to investigate the usability level of this prototype among the students. The findings show that the learners perceive the developed mobile application as usable, according to usability metrics [13].

\section{RESEARCH MethodOLOGY}

\section{A. Design and Development a Mobile Prototype}

Based on the literature, we have developed a mobilebased application prototype for learning the concept of the technical subject (Dijkstra's shortest path algorithm). The prototype started with an accompanied start-up page. The designed page and its components appear on the start-up page to attract learner interest, enhance learning assessment and provide instruction for indoor and outdoor learn- 
ing activities. The prototype serves the purpose of learning and practicing the technical subject, namely Dijkstra's algorithm, to computer science students in a way to facilitate their learning. The content pages are presented in textual and animated formats, with some simple activities designed by the researchers. The two mobile devices with different screen displays are Apple iPhone 4 as a mobile phone (operated on iPhone operating system (iOS), $640 \mathrm{x}$ 960 pixels screen display), and Acer Inconia Tab as a tablet PC (operated on an Android operating system, 1280 X 800 pixels screen display).

\section{B. Discussion on Design and Development of the Mobile Learning Prototype}

Figure 1 shows the introductory page, where users are shown an attractive introductory page and attractive buttons. Each button shows an action that each router has to perform while working on the network. The user will then be directed to the main content page of the specific action which presents basic information about the action and a main menu. The learning atmosphere is friendly, and the content page is colorful and intuitive. The main page contains an animation to encourage learners to learn about the actions. Figure 2 shows that the 4 buttons address "Learn \& Example", "Try \& Test", "Previous" and "Next", so that learners can access all steps of learning and a textual context to describe the action for students via some simple sentences. Users can select the options to 'learn about the action', followed by 'view an example' or 'test and practice the action,' to evaluate themselves by touching the buttons. 'The design allows students to have full control of the mobile learning prototype and the student lessons. After touching a button, the first page will direct students to a new content page. Based on which step is chosen, materials and contents are presented in a proportionate form so that the user can have greater interactions. Keeping the user working in an interactive manner with the prototype is our main concern [27].

After getting acquainted with the concept of Dijkstra's shortest path algorithm, users are allowed to enter the following session and learn the subject via an appropriate example. The prototype delivers the information in an

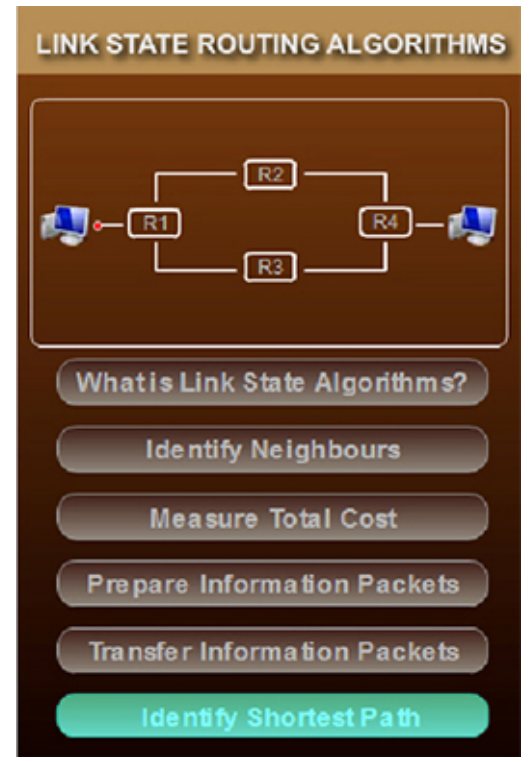

Figure 1. Intro page of the mobile application animated format. Both animation and text are used to motivate users to learn more about the subject. According to the study's aim and objectives, learners are given autonomy to control this phase of learning. Learners can evaluate themselves in the final option of this application, which allows learners to grade their performance and obtain feedback provided by the application. Animations are provided in movie clips in the content pages. Movie clips are used in this mobile-based learning application to reduce the size of the output file. The navigation is simple, user friendly and clear, and it allows navigation from any page to any other particular section and back to the main menu [27]. Despite its design and varieties of animations and buttons, an important design priority was to design a quickly-loading main page. All pages were produced to fit the screen size of the two separate small-screen mobile devices (either on Apple iPhone 4 mobile phone or Acer Inconia Tab tablet PC) before offering the prototype to the students for testing.

During the design stage, we highly consider the restrictions of small screen devices such as limited and different small screen size, as well as poor resolution during the design and development of the prototype [4],[7]. The final prototype was then presented employing these two distinctive mobile devices to computer science students as a mobile-based interactive learning and prototype to support their understanding of the subject matter and practice in their field of study. In the design phase, procedural steps define the requirements of learning application. The validity of the content comes from renowned instructional book references such as [1],[2]. Usability guidelines for designing and developing an interactive learning application based on a mobile technology environment were incorporated [6],[9],[10]. Design requirements of a usable application also include learning a technical subject based on small screen devices. Another important consideration is the usability of the learning application, as presented by [9], [10] and [11]. These design requirements were incorporated into the design and development of the mobile learning application for both mobile devices.

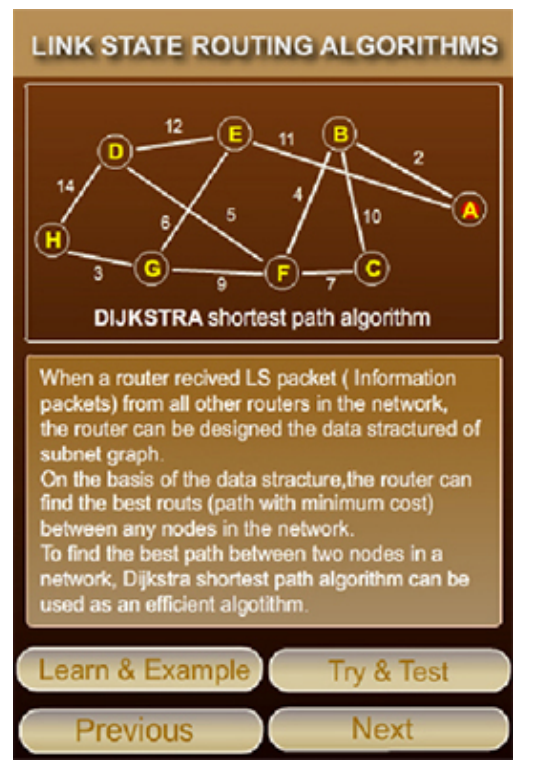

Figure 2. Main content page of link state routing algorithms 


\section{EXPERIMENTAL STUDY}

In this study, we conducted a user evaluation of the learning prototype with 30 participants with computer science backgrounds. Each of the participants was briefed to test the two different targeted mobile devices. A single task was planned to evaluate the impacts of different mobile devices on the level of user satisfaction of the prototype. We asked each participant to evaluate the prototype's performance on learning Dijkstra's shortest path algorithm with their test performance. The participants were given 5 to 10 minutes to work with the prototype before evaluating the prototype and taking the test. Subsequently, each of the participants was asked to perform a single task on another mobile device. The order of the test instruments (Apple iPhone 4 and Acer Inconia Tab) were randomly chosen to avoid bias in the experimental design.

After finishing the task on each mobile device, the participants were asked to complete a usability questionnaire to evaluate the level of user satisfaction with the mobilebased prototype for each mobile device. This questionnaire was based on the QUIS (Questionnaire for User Interaction Satisfaction) (Chin, 1998). The questionnaire consists of a set of validated questions to evaluate the level of each student's satisfaction with the mobile learning prototype. The data collected from the usability (user satisfaction) questionnaire were defined, based on usability and user satisfaction metrics. The questionnaire consists of 5 metrics, which include 'overall reaction to the prototype', 'screen', 'terminology and system information', 'learning' and system capabilities'. The students need to rate each question on a 7-point semantic differential scale. There is also another option (NA= not applicable) for those who believe the question is not relevant to the prototype. Half of the participants tested the prototype on the Apple iPhone 4 as the first device, and second half started the testing with the tablet device (Acer Inonia Tab) to ensure a high level of accuracy and avoid bias of the test results. After each session, the data were analyzed to extract appropriate information. To analyze the results, we used the SPSS 16 statistical analysis software to run the analysis. Paired-Samples T-Test was used to analyze the test and QUIS questionnaire results.

\section{RESUlts}

The data gathered through QUIS questionnaires which were completed at the end of each testing session are summarized and shown in Table I. User satisfaction with both mobile devices (Acer Inconia Tab and Apple iPhone 4) was measured on a 7-point Semantic Differential Scale. Each mobile device with the two different interface designs was classified by the users according to 5 different categories as mentioned below (see Table 1).

As mentioned previously, a Paired-Sample T-Test was used to analyze the data gathered from the QUIS questionnaire in terms of user satisfaction, (see Table I). Table II provides the usability items which show significant differences between both Acer Inconia Tab and Apple iPhone 4 mobile devices.

As shown in Table I and Table II, the tablet PC and mobile Phone have no significant differences in terms of "simple and natural sentences" and "tasks can be performed in a straight-forward manner". Both have an average mean (5.93 and 5.87), mean difference $(0.000$ and $0.000)$, T-value (0.000 and 0.000$)$ and P-value (1.000 and 1.000). Furthermore, the Mobile phone (Apple iPhone 4) scores better in terms of "efficiency" and "showing the mistakes" on the basis of user satisfaction. In other words, except for the questionnaire's 4 usability items which are addressed above, the tablet PC achieves overall better scores compared to the mobile phone (Apple iPhone 4), based on the QUIS results.

TABLE I

PARTICIPANT SATISFACTION RATING For MobiLe DeVICES

\begin{tabular}{|c|c|c|c|c|c|c|c|}
\hline Question & Mobile devices & $\mathbf{N}$ & Mean & Std. Deviation & $\mathbf{t}$ & $P$ value & $\begin{array}{c}\text { Mean } \\
\text { difference }\end{array}$ \\
\hline \multicolumn{8}{|c|}{ Category: Overall Reaction } \\
\hline \multirow{2}{*}{ Terrible-Wonderful } & Acer Inconia Tab & 30 & 5.97 & 0.809 & \multirow{2}{*}{4.558} & \multirow{2}{*}{$* * 0.000$} & \multirow{2}{*}{0.800} \\
\hline & Apple iPhone 4 & 30 & 5.17 & 1.020 & & & \\
\hline \multirow{2}{*}{ Difficult-Easy } & Acer Inconia Tab & 30 & 6.30 & 0.794 & \multirow{2}{*}{2.878} & \multirow{2}{*}{$* * 0.007$} & \multirow{2}{*}{0.667} \\
\hline & Apple iPhone 4 & 30 & 5.63 & 1.159 & & & \\
\hline \multirow{2}{*}{ Frustrating-Satisfying } & Acer Inconia Tab & 30 & 6.13 & 0.900 & \multirow{2}{*}{4.136} & \multirow{2}{*}{$* * 0.000$} & \multirow{2}{*}{1.067} \\
\hline & Apple iPhone 4 & 30 & 5.07 & 1.437 & & & \\
\hline \multirow{2}{*}{ Rigid-Flexible } & Acer Inconia $\mathrm{Tab}$ & 30 & 5.73 & 1.202 & \multirow{2}{*}{1.838} & \multirow{2}{*}{0.076} & \multirow{2}{*}{0.400} \\
\hline & Apple iPhone 4 & 30 & 5.33 & 1.213 & & & \\
\hline \multirow{2}{*}{ Dull-Stimulating } & Acer Inconia Tab & 30 & 5.53 & 1.592 & \multirow{2}{*}{0.226} & \multirow{2}{*}{0.823} & \multirow{2}{*}{0.033} \\
\hline & Apple iPhone 4 & 30 & 5.50 & 1.503 & & & \\
\hline \multirow{2}{*}{ Unfriendly-Friendly } & Acer Inconia Tab & 30 & 5.93 & 1.530 & \multirow{2}{*}{1.884} & \multirow{2}{*}{0.070} & \multirow{2}{*}{0.367} \\
\hline & Apple iPhone 4 & 30 & 5.57 & 1.501 & & & \\
\hline \multirow{2}{*}{ Ineffective-Effective } & Acer Inconia Tab & 30 & 6.00 & 0.910 & \multirow{2}{*}{2.763} & \multirow{2}{*}{$* * 0.010$} & \multirow{2}{*}{0.333} \\
\hline & Apple iPhone 4 & 30 & 5.67 & 0.959 & & & \\
\hline \multirow{2}{*}{ Inefficient-efficient } & Acer Inconia Tab & 30 & 5.97 & 0.718 & \multirow{2}{*}{-0.843} & \multirow{2}{*}{0.406} & \multirow{2}{*}{-1.700} \\
\hline & Apple iPhone 4 & 30 & 7.67 & 10.864 & & & \\
\hline
\end{tabular}


PAPER

IMPACTS OF DifFERENT MOBILE USER INTERFACES On STUDENT SATISFACTION FOR LEARNing DiJKSTRA’s SHORTEST...

\begin{tabular}{|c|c|c|c|c|c|c|c|}
\hline \multicolumn{8}{|c|}{ Category: Screen } \\
\hline \multirow{2}{*}{$\begin{array}{l}\text { On screen information } \\
\text { Confusing-Very clear }\end{array}$} & Acer Inconia Tab & 30 & 6.20 & 0.961 & \multirow{2}{*}{2.765} & \multirow{2}{*}{$* * 0.010$} & \multirow{2}{*}{0.433} \\
\hline & Apple iPhone 4 & 30 & 5.77 & 0.971 & & & \\
\hline \multirow{2}{*}{$\begin{array}{l}\text { Interaction } \\
\text { Difficult-Easy }\end{array}$} & Acer Inconia Tab & 30 & 6.20 & 0.761 & \multirow{2}{*}{3.593} & \multirow{2}{*}{$* * 0.001$} & \multirow{2}{*}{0.967} \\
\hline & Apple iPhone 4 & 30 & 5.23 & 1.406 & & & \\
\hline \multirow{2}{*}{$\begin{array}{l}\text { Sequence of Screen } \\
\text { Difficult-Easy }\end{array}$} & Acer Inconia Tab & 30 & 6.10 & 0.995 & \multirow{2}{*}{1.439} & \multirow{2}{*}{0.161} & \multirow{2}{*}{0.267} \\
\hline & Apple iPhone 4 & 30 & 5.83 & 1.053 & & & \\
\hline \multirow{2}{*}{$\begin{array}{l}\text { Reading Items } \\
\text { Difficult-Easy }\end{array}$} & Acer Inconia Tab & 30 & 6.33 & 0.802 & \multirow{2}{*}{4.227} & \multirow{2}{*}{$* * 0.000$} & \multirow{2}{*}{1.300} \\
\hline & Apple iPhone 4 & 30 & 5.03 & 1.497 & & & \\
\hline \multirow{2}{*}{$\begin{array}{l}\text { Easy to Find Learning Steps } \\
\text { Difficult-Easy }\end{array}$} & Acer Inconia Tab & 30 & 6.17 & 0.791 & \multirow{2}{*}{1.409} & \multirow{2}{*}{0.169} & 0333 \\
\hline & Apple iPhone 4 & 30 & 5.83 & 1.177 & & & ניכנ. \\
\hline Multimedia Elements & Acer Inconia Tab & 30 & 5.80 & 0.887 & 1361 & 0184 & 0200 \\
\hline Useless-Useful & Apple iPhone 4 & 30 & 5.60 & 1.037 & 1.361 & 0.184 & 0.200 \\
\hline Navigate Among the Screen & Acer Inconia Tab & 30 & 6.30 & 0.750 & 2670 & **0 012 & 0633 \\
\hline Difficult-easy & Apple iPhone 4 & 30 & 5.67 & 1.241 & 2.070 & 0.012 & ב \\
\hline & & $\log y \&$ & ystem & ack & & & \\
\hline Simple and Natural Sentences & Acer Inconia Tab & 30 & 5.93 & 0.828 & 0000 & 1000 & 0000 \\
\hline Never-Always & Apple iPhone 4 & 30 & 5.93 & 0.907 & 0.000 & 1.000 & 0.000 \\
\hline Error Messages & Acer Inconia Tab & 30 & 6.07 & 1.437 & 0.619 & 0.541 & 0.100 \\
\hline Unhelpful-Helpful & Apple iPhone 4 & 30 & 5.97 & 1.299 & 0.017 & & \\
\hline Prompt Messages & Acer Inconia Tab & 30 & 6.10 & 0.885 & 2276 & $* * 0030$ & 0333 \\
\hline Confusing-Clear & Apple iPhone 4 & 30 & 5.77 & 1.223 & $2.2 / 6$ & 0.030 & 0.353 \\
\hline Message Positions & Acer Inconia Tab & 30 & 6.33 & 0.711 & 1278 & 0.211 & 0.133 \\
\hline Inconsistent-Consistent & Apple iPhone 4 & 30 & 6.20 & 0.761 & $1.2 / 8$ & 0.211 & 0.133 \\
\hline Related Terms to the Task & Acer Inconia Tab & 30 & 6.17 & 0.747 & 0902 & 0375 & 0100 \\
\hline Never-Always & Apple iPhone 4 & 30 & 6.07 & 0.868 & 0.902 & $0.3 / 5$ & 0.100 \\
\hline Informs About Work Progress & Acer Inconia Tab & 30 & 6.27 & 0.691 & 1.606 & 0.119 & 0.433 \\
\hline Never-Always & Apple iPhone 4 & 30 & 5.83 & 1.440 & & & \\
\hline & & $y: L e$ & ning & & & & \\
\hline Learning Method & Acer Inconia Tab & 30 & 6.13 & 0.819 & 0297 & 0769 & 0033 \\
\hline Helpful-Unhelpful & Apple iPhone 4 & 30 & 6.10 & 0.845 & 0.291 & 0.107 & ( \\
\hline Help Messages & Acer Inconia Tab & 30 & 5.90 & 1.373 & 1355 & 0186 & 0333 \\
\hline Helpful-Unhelpful & Apple iPhone 4 & 30 & 5.57 & 1.851 & 1.350 & 0.186 & 0.333 \\
\hline Tasks Can be Performed in & Acer Inconia Tab & 30 & 5.87 & 1.332 & & & \\
\hline $\begin{array}{l}\text { Stralght-Forward Manner } \\
\text { Never-Always }\end{array}$ & Apple iPhone 4 & 30 & 5.87 & 1.432 & 0.000 & 1.000 & 0.000 \\
\hline Remembering Commands & Acer Inconia Tab & 30 & 6.17 & 0.834 & 1.409 & 0.169 & 0.167 \\
\hline Difficult-Easy & Apple iPhone 4 & 30 & 6.00 & 0.910 & & & \\
\hline Learning to Operate the System & Acer Inconia $\mathrm{Tab}$ & 30 & 6.40 & 0.770 & 440 & **0 0021 & 0400 \\
\hline Difficult-Easy & Apple iPhone 4 & 30 & 6.00 & 1.083 & 2.449 & 0.021 & 0.400 \\
\hline Information Delivery Method & Acer Inconia Tab & 30 & 6.17 & 0.699 & 1770 & 0096 & 0333 \\
\hline Helpful-Unhelpful & Apple iPhone 4 & 30 & 5.93 & 0.828 & 1.120 & 0.090 & בני \\
\hline & & licatio & capabi & & & & \\
\hline System Speed & Acer Inconia Tab & 30 & 6.33 & 0.802 & 1795 & 0083 & 0300 \\
\hline Too Slow-Fast Enough & Apple iPhone 4 & 30 & 6.03 & 1.033 & 1.195 & 0.083 & 0.300 \\
\hline System Reliability & Acer Inconia Tab & 30 & 5.93 & 1.741 & 2757 & **0010 & 0300 \\
\hline Unreliable-Reliable & Apple iPhone 4 & 30 & 5.63 & 1.712 & 2.151 & 0.010 & 0.300 \\
\hline Showing Your Mistakes & Acer Inconia Tab & 30 & 5.93 & 1.780 & -0.126 & 0.901 & -0.033 \\
\hline Never-Always & Apple iPhone 4 & 30 & 5.97 & 1.450 & & & \\
\hline Experienced and Inexperienced & Acer Inconia Tab & 30 & 5.57 & 1.695 & & & \\
\hline $\begin{array}{l}\text { Users' Consideration } \\
\text { Never-Always }\end{array}$ & Apple iPhone 4 & 30 & 5.53 & 1.756 & 0.239 & 0.813 & 0.033 \\
\hline
\end{tabular}

$* * \mathrm{P}<0.05$ 
PAPER

IMPACTS OF DiFFERENT MOBILE USER INTERFACES ON STUDENT SATISFACTION FOR LEARNING DiJKSTRA’S SHORTEST...

TABLE II.

RESULTS OF USERS’ SATISFACTION TOWARDS THE TWO MOBILE SCREEN INTERFACES

\begin{tabular}{|c|c|}
\hline Terms & $\begin{array}{l}\text { Results in Pair Sample T-Test } \\
\text { (Note: Acer Inconia Tab=Table PC; Apple iPhone4=mobile phone) }\end{array}$ \\
\hline Terrible-Wonderful & $\begin{array}{l}\text { Significant difference for Tablet } \mathrm{PC}(\mathrm{M}=5.97, \mathrm{SD}=0.809) \text { and mobile phone }(\mathrm{M}=5.17, \mathrm{SD}=1.020) \text { condi- } \\
\text { tions, } \mathrm{t}(29)=4.558, * * \mathrm{P} \text { value }=0.000 \text {. }\end{array}$ \\
\hline Difficult-Easy & $\begin{array}{l}\text { Significant difference for Tablet } \mathrm{PC}(\mathrm{M}=6.30, \mathrm{SD}=0.794) \text { and mobile phone }(\mathrm{M}=5.63, \mathrm{SD}=1.159) \text { condi- } \\
\text { tions, } \mathrm{t}(29)=2.878, * * \mathrm{P} \text { value }=0.007 \text {. }\end{array}$ \\
\hline Frustrating-Satisfying & $\begin{array}{l}\text { Significant difference for Tablet } \mathrm{PC}(\mathrm{M}=6.13, \mathrm{SD}=0.900) \text { and mobile phone }(\mathrm{M}=5.07, \mathrm{SD}=1.437) \text { condi- } \\
\text { tions, } \mathrm{t}(29)=4.136, * * \mathrm{P} \text { value }=0.000 \text {. }\end{array}$ \\
\hline Ineffective-Effective & $\begin{array}{l}\text { Significant difference for Tablet } \mathrm{PC}(\mathrm{M}=6.00, \mathrm{SD}=0.910) \text { and mobile phone }(\mathrm{M}=5.67, \mathrm{SD}=0.959) \text { condi- } \\
\text { tions, } \mathrm{t}(29)=2.763, * * \mathrm{P} \text { value }=0.010 \text {. }\end{array}$ \\
\hline Inefficient-Efficient & $\begin{array}{l}\text { NO significant difference for the two mobile devices, } \mathrm{t}(29)=-0.843, \mathrm{P} \text { value }=0.406 \text {. The mobile phone is } \\
\text { more efficient than the Tablet } \mathrm{PC} \text {. }\end{array}$ \\
\hline On Screen Information & $\begin{array}{l}\text { Significant difference for Tablet } \mathrm{PC}(\mathrm{M}=6.20, \mathrm{SD}=0.961) \text { and mobile phone }(\mathrm{M}=5.77, \mathrm{SD}=0.971) \text { condi- } \\
\text { tions, } \mathrm{t}(29)=2.765, * * \mathrm{P} \text { value }=0.010 \text {. }\end{array}$ \\
\hline Interaction & $\begin{array}{l}\text { Significant difference for Tablet } \mathrm{PC}(\mathrm{M}=6.20, \mathrm{SD}=0.761) \text { and mobile phone }(\mathrm{M}=5.23, \mathrm{SD}=1.406) \text { condi- } \\
\text { tions, } \mathrm{t}(29)=3.593, * * \mathrm{P} \text { value }=0.001 \text {. }\end{array}$ \\
\hline Reading Items & $\begin{array}{l}\text { Significant difference for Tablet } \mathrm{PC}(\mathrm{M}=6.33, \mathrm{SD}=0.802) \text { and mobile phone }(\mathrm{M}=5.03, \mathrm{SD}=1.497) \text { condi- } \\
\text { tions, } \mathrm{t}(29)=4.227, * * \mathrm{P} \text { value }=0.000 \text {. }\end{array}$ \\
\hline Navigate Among the Screen & $\begin{array}{l}\text { Significant difference for Tablet } \mathrm{PC}(\mathrm{M}=6.30, \mathrm{SD}=0.750) \text { and mobile phone }(\mathrm{M}=5.67, \mathrm{SD}=1.241) \text { condi- } \\
\text { tions, } \mathrm{t}(29)=2.670, * * \mathrm{P} \text { value }=0.012 \text {. }\end{array}$ \\
\hline Simple and Natural Sentences & $\begin{array}{l}\text { NO difference for both mobile devices, } \mathrm{t}(29)=0.000, \mathrm{P} \text { value }=1.000 . \text { In this condition, both devices are } \\
\text { equal. }\end{array}$ \\
\hline Prompt Messages & $\begin{array}{l}\text { Significant difference for Tablet } \mathrm{PC}(\mathrm{M}=6.10, \mathrm{SD}=0.885) \text { and mobile phone }(\mathrm{M}=5.77, \mathrm{SD}=1.223) \text { condi- } \\
\text { tions, } \mathrm{t}(29)=2.276, * * \mathrm{P} \text { value }=0.030 \text {. }\end{array}$ \\
\hline $\begin{array}{l}\text { Tasks Can be Performed in Straight- } \\
\text { Forward Manner }\end{array}$ & $\begin{array}{l}\text { NO difference for both mobile devices, } \mathrm{t}(29)=0.000, \mathrm{P} \text { value }=1.000 . \text { In this condition, both devices are } \\
\text { equal. }\end{array}$ \\
\hline Learning to Operate the System & $\begin{array}{l}\text { Significant difference for Tablet } \mathrm{PC}(\mathrm{M}=6.40, \mathrm{SD}=0.770) \text { and mobile phone }(\mathrm{M}=6.00, \mathrm{SD}=1.083) \text { condi- } \\
\text { tions, } \mathrm{t}(29)=2.449, * * \mathrm{P} \text { value }=0.021 \text {. }\end{array}$ \\
\hline System Reliability & $\begin{array}{l}\text { Significant difference for Tablet } \mathrm{PC}(\mathrm{M}=5.93, \mathrm{SD}=1.741) \text { and mobile phone }(\mathrm{M}=5.63, \mathrm{SD}=1.712) \text { condi- } \\
\text { tions, } \mathrm{t}(29)=2.757, * * \mathrm{P} \text { value }=0.010 \text {. }\end{array}$ \\
\hline Showing Your Mistakes & $\begin{array}{l}\text { NO significant difference for both mobile devices, } t(29)=-0.126, \mathrm{P} \text { value }=0.901 \text {. The mobile phone is } \\
\text { more efficient than the Tablet PC. }\end{array}$ \\
\hline
\end{tabular}

$* * \mathrm{P}<0.05, \mathrm{df}=29$

\section{DISCUSSION}

This study focuses on students' usability satisfaction for mobile-based learning prototype based on the impacts of two different mobile devices for learning a technical subject called Dijkstra's shortest path algorithm. With this goal in mind, we investigated and compared the impacts of these two mobile devices on the level of user satisfaction employing the QUIS usability questionnaire to compare tablet PCs (Acer Inconia Tab) with mobile phones (Apple iPhone 4).

All users worked with the same mobile-based learning prototype and performed the same task each learning and testing session. In general, the Acer Inconia Tab with its bigger screen size, faster reaction, and better clarity of the contexts gained higher scores as compared to Apple iPhone 4 mobile phone in terms of 'overall reaction to the application', 'screen', 'terminology and system feedback', 'learning and application capabilities'. This falls within our expectations as tablet PCs generally have a larger screen display (1280 x 800 pixels) than mobile phones (640 x 960 pixels) that triggers a better system reaction and performance for users interacting with the tasks at hand.

This study examined user satisfaction with both mobile devices for learning a technical subject. Results show that the Acer Inconia Tab and Apple iPhone 4 share the same score in terms of "simple and natural sentences" and "task can be performed in a straight-forward manner".
However, it is interesting to learn that the Apple iPhone 4 gained better satisfactory scores in terms of "efficiency" and "showing the mistakes" on the basis of user satisfaction questionnaire. The feedback gathered indicates that the Apple iPhone 4 could be more portable, attractive and responsive in showing errors. Apart from the above mentioned 4 items, the Acer Inconia Tab generally scored better for overall items as compared to Apple iPhone 4 .

Based on the finding of this research study, we recommend "if a learning application is to be developed based on mobile phones, there are some factors that should be considered by the designers and developers. Users must be able to change the screen size of the application. The application should be able to tilt to a landscape size by the users".

The small size of the buttons and texts, the lack of sound effects and landscaping ability of the prototype, and the changing size of the screen are the main reasons the learning prototype was not preferred, and users were not satisfied with the prototype when presented through the mobile phone.

\section{CONCLUSION}

The goal of this research was to investigate and compare the impacts of different mobile devices on user satisfaction among computer science students learning Dijkestra's shortest path algorithm. We noticed that the Acer Inconia Tab, representative of the tablet PC family, is 
found to be more useful in learning Dijkestra's shortest path algorithm than the Apple iPhone 4, an example of the touch-based mobile phone family. Users were more satisfied using the tablet device than a mobile phone because of the tablets' larger screen size and the better clarity of information presented. Significantly, however, participants perceived that the mobile phone was more efficient as the results of QUIS questionnaire show that the efficiency of the mobile phone was greater than that of the tablet PC.

Generally, the two mobile devices were presented as a testing tool for computer science students to learn a technical subject and measure their usability level and impacts on user satisfaction scores. Therefore, it is important to investigate the level of user satisfaction of the two mobile devices based on different sizes of screen interface. Apart from this, interactivity, multimedia elements and usable system feedback are three factors that improve user satisfaction results and make better engage students to interact with the application. Consequently, it is important the content shown on the tablet PCs with bigger screen size to be interactive and simple to provide users greater control of the application to stimulate their learning process.

In conclusion, future research is essential to investigate the impacts of small screen interfaces on user satisfaction. The first of this study's 3 groups learned a specific technical subject in a face-to-face classroom, the second group of students learns the subject using tablet PCs and the third group of students learned the subject with a combination of face-to-face classrooms and tablet PCs. Future study will include performing a single test and evaluate each group of students to figure out which approach or technology has the greatest user satisfaction. Future research will also include an Internet-based mobile learning application to provide a more robust interaction between lecturers and students that better communicates students with fewer time and location constraints.

\section{REFERENCES}

[1] A. S. Tanenbaum, Computer networks, 4rd ed., United States of America: Pearson Education, 2003.

[2] B. A. Forouzan, and S. C. Fegan, Data communication and computer networks, 4th ed., New York: McGraw-Hill, 2007.

[3] A. Drigas, L. Koukianakis, and Y. Papagerasimou, "A web based e-learning and e-psychology modular environment," Proceedings of International Conference on Next Generation Web Services Practices, pp. 168-174, 2006. http://dx.doi.org/10.1109/ NWESP.2006.5

[4] M. Fetaji, "Case Study: Analyses of factors that influence mobile applicative software," Proceedings of World Conference on Educational Multimedia, Hypermedia and Telecommunications, vol. 2008, pp. 1468-1475, 2008a.

[5] G. N. Vavoula, P. Lefrere, C. O'Malley, M. Sharples, and J. Taylor, "Producing guidelines for learning, teaching and tutoring in a mobile environment," In Proceedings of the 2nd IEEE International Workshop on Wireless and Mobile Technologies in Education (WMTE' 04), pp. 173-176, 2004.

[6] M. Fetaji, "Devising a strategy for usability testing of M-Learning applications," Proceedings of World Conference on Educational Multimedia, Hypermedia and Telecommunications, vol. 2008, pp. 1393-1398, 2008b.

[7] H. Z. Ye, R. Li, and M. L. Geng, "Research on the factors of affecting The mobile learning," 3rd International Symposium on Knowledge Acquisition and Modeling, pp. 313-316, 2010.

[8] K. B. Lee, and R. A. Grice, "Developing a new usability testing method for mobile devices," In Proceedings of the 23rd International Performance, Computing, and Communications Conference (IPCCC'04), Phoenix, Arizona, pp. 115-127, 14-17 April 2004.

[9] D. S. K. Seong, "Usability Guidelines for Designing Mobile Learning Portals," The University of Nottingham, Malaysia. The 3rd International Conference on Mobile Technology, Application and Systems - Mobility 2006.

[10] A. Grasso, and T. Roselli, "Guidelines for Designing and Developing Contents for Mobile Learning," Proceedings of the 2005 IEEE International Workshop on Wireless and Mobile Technologies in Education (WMTE '05). E. H. Miller, pp. 123-127, November 2005 .

[11] J. Nielsen, Usability Engineering. Morgan Kaufman Publisher, Academic Press, 1993.

[12] M. Fetaji, "Designing usable M-learning application: mobile view case study," Proceedings of World Conference on Educational Multimedia, Hypermedia and Telecommunications, vol. 2008, pp. $1251-1256,2008 \mathrm{c}$.

[13] A. S. Hashim, W. F. W. Ahmad, and A. Rohiza, "A study of design principles and requirements for the m-learning application development," International conference on User Science and Engineering (i-USEr), pp. 226-231, 2010.

[14] ISO/CDS 9241-11, Guidelines for specifying and measuring usability, 1993.

[15] ISO/IEC 9241-11, Ergonomic Requirements for Office Work with Visual Display Terminals (VDT)s - Part 11 Guidance on Usability, 1998: ISO/IEC 9241-11: 1998 (E), 1998.

[16] Y. Jun, and H. Zhi-yi, "Learning anywhere anytime with mobile devices," Artificial Intelligence and Education (ICAIE), pp. 768771, 2010.

[17] M. Hentea, "Research on the factors of affecting the mobile learning," Information Technology: Research and Education, pp. 91-95, 2004.

[18] J. P. Chin, V. A. Diehl, K. L. Norman, "Development of an instrument measuring user satisfaction of human-computer interface," CHI '88: Proceedings of the SIGCHI conference on Human factors in computing systems, pp. 213-218, 1988

[19] F.B. Anaraki, "A flash-based mobile learning system for learning english as a second language," International Conference on Computer Engineering and Technology, pp.400-404, 2009.

[20] T. H. Tan, and T. Y. Liu, "The Mobile-based interactive learning environment (MOBILE) and a case study for assisting elementary school english learning," Proceedings of the IEEE International Conference on Advanced Learning Technologies (ICALT'04), pp.530-534, 2004.

[21] L. Repokari, T. Saarela, and I. Kurki, "Visual search on a mobile phone display," In Proceedings of the 2002 Annual Research Conference of the South African Institute of Computer Scientist and Information Technologists on Enablement through Technology, SESSION: Abstracts for short papers: human-computer interaction and visualization. Port Elizabeth, South Africa. New York: ACM Press, pp. 253-254, 2002.

[22] D. K. S. Su, and F. C. Chan, "Navigational patterns on usable mobile news portals," Journal of Internet Technology, vol. 7, pp. 230-237, 2006.

[23] G. Buchanan, S. Farrant, M. Jones, H. Thimbleby, G. Marsden, and M. Pazzani, "Improving mobile Internet usability," In Proceedings of the 10th International Conference on the World Wide Web. New York: ACM Press, pp. 673-680, 2001.

[24] W. A. Kellogg, "Conceptual consistency in the user interface: Effects on user performance," In Proceedings of IFIP INTERACT'87 2nd International Conference of HumanComputer Interaction, pp. 389-394, 1987.

[25] A. Kaikkonen, and J. Laarni, "Designing for small display screens," In Proceedings of the 2nd Nordic Conference on HumanComputer Interaction. Aarhus, Denmark, New York: ACM Press, pp. 227- 230, 2002. http://dx.doi.org/10.1145/572020. 572052

[26] D. Parsons, H. Ryu, and M. Cranshaw, "A Design Requirement Framework of Mobile Learning Environments," Journal of Computers, vol. 2, pp. 1-8, 2007. http://dx.doi.org/10.4304/jcp.2.4.1-8

[27] M. Seraj, C. Y. Wong, "A study of user interface design principles and requirements for developing a mobile learning prototype," International Conference on Computer and Information Science (ICCIS), pp.1014-1019, 2012.

\section{AUTHORS}

Mazyar Seraj is with Limkokwing University of Creative Technology, Malaysia.

Chui Yin Wong is with Multimedia University Malaysia.

Submitted 11 May 2014. Published as resubmitted by the authors 14 October 2014. 